\title{
Quality management as the basis of business company operations for the purpose of customer satisfaction
}

\author{
Elma Avdagić-Golub, Adisa Hasković Džubur, Belma Memić \\ ${ }^{1}$ University of Sarajevo, Faculty of Traffic and Communiactions, Zmaja od Bosne 8, 71000 Sarajevo
}

\begin{abstract}
Nowadays, companies face numerous challenges to operate successfully and remain competitive in the market. Globalization is increasing competition in the market, allowing many companies to operate in foreign markets. Increasing competition has made companies constantly trying to increase their productivity while reducing costs. To meet all the requirements, and at the same time function in the best possible way, companies must be organized adequately, taking into account the whole set of processes from the company's internal organization to the company's appearance on the market. It means, if the end-user is to be satisfied, the company must implement quality in all phases of business, ie business ethics and company culture, through the quality of technology, personnel, etc. In other words, it must be satisfied the system quality of the company, known in the literature as QMS (Quality Management System). The main purpose of this paper is to review the multiple understanding of the concept of QMS and its different underpinning theories in a business to customer context. The design of this research is based on mere documentary analysis and some observations.
\end{abstract}

Keywords: QMS, QoS, service providers, management, customers

\section{Introduction}

One of the important tasks of today's business is to understand customers, recognize their needs and desires, meet them, and at the same time try to exceed their expectations. Therefore, the view of the customer or service user is taken as the basis for defining the new quality concept. The term "quality" comes from the Latin word qualities, whose basic meaning is - property, property, value. Quality has grown out of a fundamentally new, scientific view of work. It is not the scientific management of Frederick Winslow Taylor from the early twentieth century, who first applied scientific methods to rationalize and increase labor productivity and described them in his books [1]. In the approach of Taylor and other writers of classical management theory, of whom the French scientist Henry Fayol stood out in Europe, quality was ensured by inspecting raw materials at the beginning and finished products at the end of the production cycle [2]. Over time, engineers and technologists have found new and more technically perfect and sophisticated control methods, but little has changed in approach over time. The generally accepted, indisputable, but also one of the shortest definitions of quality is: "Quality is customer satisfaction" [3]. Although quality managers have dealt with the very appearance of modern companies, overall quality management as a concept and program has been more clearly shaped only in recent decades, with the fact that these are processes that are continuously upgraded and supplemented.

A set of tools and processes whose outputs bring consumer satisfaction and continuous improvement is the philosophy of Total Quality Management. All members of the total quality of the organization strive to improve the business through the participation of all members in problem-solving in all parts of the organization. Concept holders of TQM (Total Quality Management) in the company are all employees. All employees are responsible for reaching quality standards. According to this concept, formal control systems are abolished. The basis of TQM is the principles of the Quality Management System - QMS, which we discuss in this paper.

\section{Quality Management System - QMS}

Concept QMS is a quality management system and it is basically a management function. This also affects the company's competitive position in the market and strengthens the trust of users themselves. This means that quality management includes all measures for organizing, planning, controlling, and displaying aspects relevant to quality [4]. Orientation towards quality, ie towards the 
establishment of a quality management system is not a binding category. However, today's market trends, whether global, regional, or local, and especially in the context of globalization and market liberalization in countries in transition, have imposed product/service quality as an imperative, but also as a guarantee or security for customers for a particular product/service. It is these requirements that the company's business can meet according to the basic principles of QMS.

\subsection{QMS and ISO standards}

The basic principles of quality management are the foundations on which the ISO 9001 certificate is built, which was developed by an international organization responsible for maintaining ISO quality management standards [5]. Therefore, the introduction of QMS for companies implies acceptance of the ISO 9000 standard and efforts to maintain it. The company's management should decide and accept all guidelines arising from the ISO 9000 standard.

According to the ISO 9000 standard, eight quality management principles have been identified that management can use in running an organization, in order to improve performance. These principles are [6]:

- Customer/user orientation: organizations depend on their customers/users and should therefore turn to them completely. This means understanding the current and future needs of their customers/users, meeting their requirements, and striving to provide more than they expect.

- Leadership: Leaders-leaders should establish unity of purpose and leadership of the organization. They need to establish and maintain such an environment, in which employees can fully participate in achieving the goals of the organization.

- Employee participation: employees at all levels form an essential part of an organization, company and only their full engagement allows their abilities to be used to achieve the benefits of the organization.

- Process approach: the planned result can be achieved more efficiently if the management of appropriate activities and resources is achieved as a process.

- Systemic approach to management: identifying and understanding a system of interconnected processes and managing that system contribute to the effectiveness and efficiency of the organization in achieving its goals.
- Continuous improvement: continuous improvement of the overall performance of the organization should be its constant goal.

- Decision making based on facts: decision making should be based on analysis of available data and information.

- Mutually beneficial relationships with suppliers: The organization and its suppliers are independent, so mutually beneficial relationships increase the ability of both to create value.

ISO 9001 and ISO 9004 standards pay special attention to customers / users, the implementation of ISO 9001 standards on service companies, we can conclude that the service company must identify:

- service requirements specified by the user,

- service requests not specified by the user, which are necessary for the specified requests to be fulfilled,

- requirements arising from laws and regulations and any other additional requirements that need to be met and exceed user expectations.

To properly identify these requirements, the service company must find effective solutions to communicate with customers/users. Therefore, in the process of achieving the desired level of customer satisfaction, and adequate relationship must be established between the employees who participate in the process of providing service and support and the customer. The ISO 9000 system of standards encompasses several requirements, which are remarkably logically interconnected and which are a kind of sublimation of the management practices of successful companies.

These eight principles of quality management form the basis for the standards of the quality management system, within ISO 9000. The main goal of the quality management system is to instill confidence in customers/users and that the business works well. The system requires the organization to demonstrate its ability to meet customer requirements as well as legal requirements. Records showing how well done in the past can give potential users a high degree of trust. The standard provides a framework for good management practice that can be applied to a business because it specifies a set of things to include. However, the standard did not take the form of how to do that, so the company was left free to meet the requirements of the standard. Therefore, it is the most efficient to build a quality management system around already existing business practices, that is, what and how is currently being done. 


\subsection{Structure of QMS}

There are eight principles of a quality management system (Figure 1), which can be applied to service and production companies [7]. They form a consistent network system, which in such an assembly gives full effectiveness and efficiency. Failure to comply with only one principle and the corresponding requirements endangers the overall management system.

\subsubsection{Customer orientation and participation of employees}

It is necessary to research the expectations of users and their opinions. One of the most relevant ways is to obtain data from users through questionnaires. Questionnaire analysis identifies elements of services that need to be improved. It is no coincidence that the first principle of QMS is: "customer focus" because with the requirements of the user and his wishes, everything starts, and with his satisfaction, all processes end. Today, modern techniques of surveying users are applied during each of his interactions with the company, using appropriate answering machines. When surveying the user, the company should take care that the user does not become strenuous and does not cause the opposite effect. Modern survey methods allow the collection of a large amount of user data, which must then be used in the right way. This is a special challenge and maybe the subject of some future work. $t$ is no coincidence that the first principle of QMS is: "customer focus" because with the requirements of the user and his wishes, everything starts, and with his satisfaction, all processes end. All employees should be familiar with the results of the survey, because only by engaging all employees can customer satisfaction be maintained and improved. Eg. if a telecommunications service company is considered, customer support is a key part of the system. If, when reporting a user problem, the operator receiving the call does not communicate with the user in a satisfactory manner, user dissatisfaction may occur regardless of the technical performance of the service. One should always be guided by the idea that one dissatisfied user can inform a large number of other users (or potential users), so the word about dissatisfaction with services spreads further and the number of lost potential users multiplies. This is especially pronounced nowadays where virality through social networks is extremely prevalent.

Establishing a QMS system in companies is not an easy process. It requires, as already mentioned, the engagement of all available human resources as well as the investment of large material resources. Therefore, those companies that introduce this system expect significant improvements in business processes (simplification and acceleration), ensuring a stable position in the market as well as achieving a satisfactory profit as a measure of a positive and successful business.

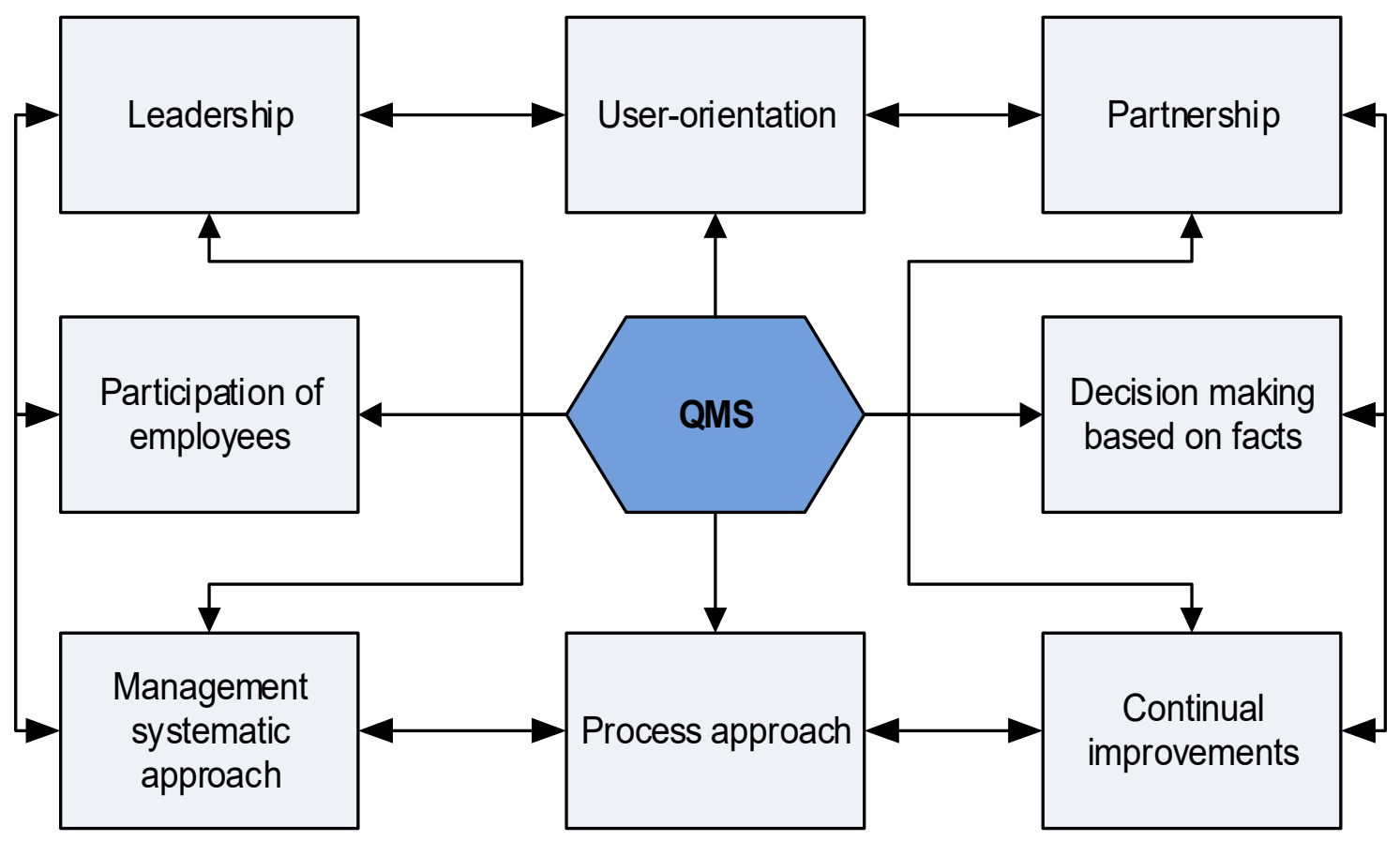

Figure 1. Principle structure of QMS [7] 


\subsubsection{Process Approach}

If the management of a service company wants to function efficiently, it is necessary to identify and manage numerous activities (processes) that are interconnected. A business process is an interaction between people, equipment, methods, and control, with the purpose of achieving a specific goal. Business processes can be divided according to importance (key processes and subprocesses) and according to content (management processes, main - basic processes, improvement processes, support processes) [8].

Key processes are processes that are important to the organization, and which directly create values for the user and other stakeholders. Subprocesses represent the concretization of key processes and include technological, administrative, or logistical tasks or operations [9].

By reviewing different sources of literature, business processes by content could be divided into four categories:

- Management processes [10]: these are "vertical" processes related to the vision, mission, policy, goals and strategy, including operational activities, tasks, resources and administration at the level of the entire organization.

- Main (basic) processes [11]: these are "horizontal" processes that result in a product or service. These processes add value to a product or service that an organization produces for its customers. These processes are procurement from suppliers, production, sales, etc.

- Improvement processes [12]: these are processes of a generic nature that plan, organize, monitor and control the activities of the organization as a whole as well as the business results of the organization. Such processes are human resource management, planning, internal control, etc.

- Support processes [10]: these processes do not add value, but their development is necessary to ensure that the main processes function as efficiently and effectively as possible. These processes are accounting, legal support, IT support, etc.

We can conclude that using this process approach in the quality management system emphasizes the importance of:

- understanding and meeting requirements,

- the need to consider the process in terms of added value,

- obtaining results of the performance and effectiveness of the process and
- continuous improvement of the process based on objective measurements.

So we need the principle of process management, as one of the industrial management approaches to improve quality and efficiency in services [13], [14]. Easier management of the mentioned processes has produced a number of models that are used to manage them. The ISO 9001 standard has adopted the PDCA model of quality management system because it emphasizes support processes, not just the main processes. This model takes such a view, in which everything related to quality begins and ends with customers/users. It was popularized by William Edwards Deming, an American quality management expert in the field of 1950 known as the Deming Circle, Deming's PDCA model (Plan - Do Check - Act Cycle) on which the quality management system model is based (Figure 2).

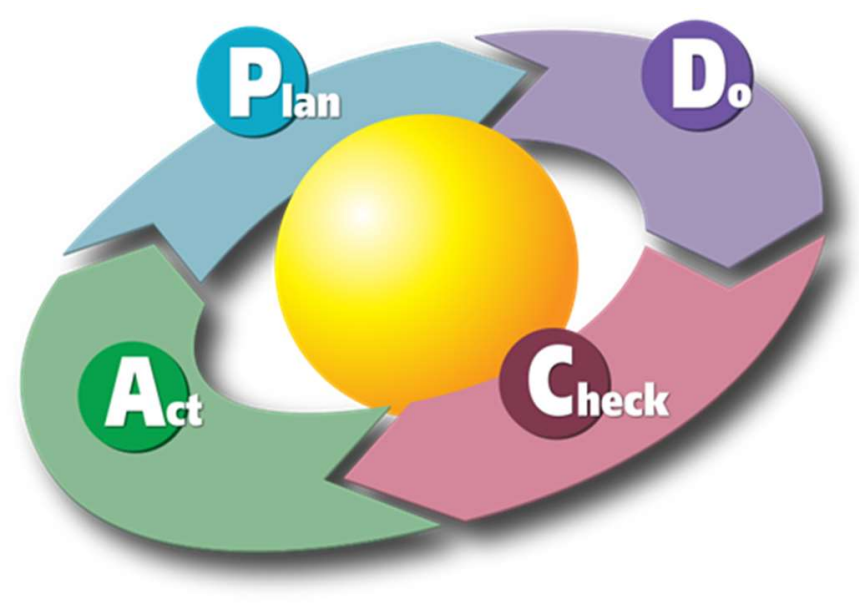

Figure 3: Model PDCA [15]

The PDCA model (plan, do, check, act) can be applied to all processes. The PDCA model includes activities with the following content [16]:

- Plan: set goals and processes and provide the resources necessary to achieve results in accordance with customer requirements and organizational policy.

- Do: implement the process, ie do what is planned.

- Check: Monitor and measure processes and products against product policies, objectives and requirements, and report results.

- Act: take action to continuously improve process performance

An objective application of PDCA method can result in the removal of waste in the workplace (reduction of waiting time, standstill, energy consumption, engine damage, losses, deficiencies, etc.), linking productivity 
and improvement, while subjective application of PDCA method requires great commitment to the process. means that the Plan, Execution, Verification, and Action must be carried out continuously [17].

\subsubsection{Documentation of QMS}

The quality management system according to the ISO 9000 standard is a documented system that includes the creation, maintenance and control of documents [6]. The basic principles of quality management, organization and individual harmonized measures must be defined and presented in writing [18].

Each organization determines the amount of documentation required as well as the media to be used. It primarily depends on the type and size of the organization, the complexity and interaction of processes, the complexity of products/services, customer requirements, etc. It is necessary to identify and define business processes, differentiate them into main processes and support processes and establish their sequence. The degree to which a particular process will be detailed depends on the complexity and stability of the main processes, and the basic requirements of ISO 9001 in terms of quality management system documentation are met through quality policy and objectives, rules of procedure and basic procedures.

The Rules of Procedure contain complete information on quality policy, rules of organizational structure, defined competence (responsibility) for quality affairs, quality measures and regulations as well as documentation and supervision of the quality management system and internal controls (audits) [19]. The Rules of procedure also state what is being done and how, and who is responsible for that, with instructions on how to do it. The Rules of Procedure on Quality also contain an overview of workflows from the point of view of quality management. It should cover all applicable elements of the ISO 9001: 2008 standard [18]. The Rules of Procedure on Quality reflect the attitude of management and all employees towards customers/users of services offered on the market.

\section{A critical review of the Correlation between QoS and QMS as a tool for managing user perception}

For each process performed in the company, it is necessary to establish procedures, ie procedures that describe the course of process execution. Regardless of how the course of process execution is described with regard to the organizational structure, it is necessary to define one or more parameters as indicators of process execution, on the basis of which it will be possible to control the execution of that process.

As an example, we can take the troubleshooting process. Under interference, we can define any disturbance that leads to the user not being able to use the service normally. It is in the interest of the user and the operator to eliminate this situation as soon as possible and to establish normal use of the service. The quality management system requires that this process be demonstrated by a procedure. This process can take place through several organizational units and in that case each of the organizational units should have its own procedure in which the activities performed in that unit are given as well as the procedures for performing these activities. In order to monitor the execution of the process, it is necessary to introduce parameters that will enable process management. The quality parameters defined by the recommendations specific to the services offered by the given company can be used for the troubleshooting process. Also, other parameters that the company deems necessary can be taken for this process. For the troubleshooting process, one of the important performances is the number of disturbances over a period of time. The time for which the fault is rectified can be taken as another parameter within the process, eg target values for parameters are set and in this way a connection is established between service quality and quality management system, ie QoS - QMS correlation is established.

Based on the above examples, it can be concluded that the relationship between service quality and quality management system, ie the correlation of QoS and QMS can be fully established. The quality of the service also includes the perception of the user, ie the parameters that reflect the perception, ie the "experience" of the delivered service. In the given examples, examples of some parameters that have a significant impact on the user's perception are given. Establishing a connection between the quality of service and the quality management system, ie the correlation QoS - QMS enables the introduction of the concept of user perception in business practice. Therefore, the QoS-QMS correlation becomes a mechanism for managing user perception.

By establishing a QoS-QMS correlation, service companies ensure that in their technological processes the quality of service is set as an obligation in the performance of work, which essentially means managing the perception of users. In this way, the user is placed in the focus of the business, ie all activities are directed in order to meet the requirements of the user, which achieves his satisfaction through a positively perceived service, and thus ensures his loyalty.

The way to continuously improve quality is to establish the TQM (Total Quality Managemet) concept as an upgrade to the principles of QMS (Quality Managemet 
System). Tasks in the establishment of TQM in the organization are: top management, middle and lower management, experts (professionals) for quality management and external consultants. In addition to these traditional ones, TQM is looking for some new roles in the organization, such as TQM leading team, process engineering, TQM manager, TQM project teams, quality circles, application of scientific methods, load elimination, uniformity of development and technologies and transparency of the organization. Satisfaction of QMS, as a prerequisite for full TQM will be the topic of future papers.

\section{Conclusion}

Companies successfully implement quality only when they accept it as a change of organization. Quality is the organizational learning of the user's wishes and ways to implement them. It is a specific type of learning. Only changes that bring such a state not only all parts and levels of the organization but also all its partners, will lead to the overall quality.

In the first part of this paper, the authors presented quality management as an important part of the competitiveness of the economy in the global market. In the second part, the authors discuss the structure and strategic importance of the quality management system from the perspective of the company. In the third part, the authors look at the state of application of the ISO 9001 quality management system in service companies. Finally, the authors draw conclusions about the process of implementing quality management systems in service companies, with a critical review of the Correlation between QoS and QMS.

QMS principles can be used as a basis for leading an organization and improving performance. The concept of QMS can be used as a foundation to guide an organization's performance improvement.

There are three key elements of the service company: the user (his perception), the quality of the delivered service, and the processor orientation are the basic features of the user perception management system. By implementing this system, service companies make a commitment, and at the same time give a guarantee to customers for the services they provide, which also has a positive effect on customer perception. Those companies that take customer orientation as their strategy through the management of the user perception process and set quality as an imperative can ensure a high level of user perception, which will cause customer satisfaction, which is the basis of customer loyalty. It will also secure a place in the service market, provide satisfactory business results, thus their survival and business in the future is not in question.
The service organization also constantly reviews the identification of requirements, innovated requirements, and the compliance of identified requirements with contracts. It is especially important that the management of the service organization constantly reviews whether the service organization has the readiness and capacity to meet customer requirements.

\section{References}

[1] R. Luburić, "Total Quality Management as a Paradigm of Business Success," Journal of Central Banking Theory and Practice, vol. 3(1), pp. 59-80, 2014.

[2] T. Morden, Principles of Management 2nd Edition, Routledge, 2004.

[3] J. M. Juran and F. M. Gryna, Planiranje i analiza kvalite, treće izdanje, Zagreb: Mate, 1999.

[4] T. K. Leong and N. Zakuan, "Review of quality management system research in construction industry," Int. J. Productivity and Quality Management, Vols. Vol. 13, No. 1, 2014.

[5] J. Priede, "Implementation of Quality Management System ISO 9001 in the World and Its Strategic Necessity," Procedia - Social and Behavioral Sciences, vol. 58, pp. 14661475, 2012.

[6] I. O.f. Standardization, "Quality management principles," ISO Central Secretariat, Switzerland, 2015.

[7] R. Luburić, "Quality Management Principles and Benefits of their Implementation in Central Banks," Journal of Central Banking Theory and Practice, vol. 3, pp. 91-121, 2015.

[8] I.KANIŠKI and I.VINCEK, "Business processes as business systems," Tehnički glasnik, vol. 12, no. 1, pp. 55-61, 2018.

[9] O. Prokopenko, A. Dikiy, N. Butenko, M. Naumenko, T.Dedilova and R.Miroshnyk, "Business process optimization based on logistics concepts and technologies," International Journal of Advanced Research in Engineering and Technology, vol. 11, no. 6, pp. 184-196, 2020.

[10] D. S. Bright, A. H. Cortes, E. Hartmann, P. Parboteeah and J. L. Pierce, Principles of Management, Houston, Texas: Open Stax Rice University, 2019.

[11] M. Habib, "Supply Chain Management (SCM): Theory and Evolution," InTech, 2011.

[12] C. C. Villazón, L. S. Pinilla, J. R. O. Olaso and N. T. G. a. N. d. Lacalle, "Identification of Key Performance Indicators in Project-Based Organisations through the Lean Approach," 
Sustainability, MDPI, Open Access Journal, vol. 12, no. 15, pp. 1-19, 2020.

[13] J. W. M. B. a. G. V. J. M. H. Vissers, "A framework for production control in health care organizations," Prod. Plan. Control, vol. 12, no. 6, pp. 591-604, 2001.

[14] T. W. a. D. Wainwright, "Communicating the complexity of computer-integrated operations," Int. J. Oper. Prod. Manag., vol. 22, no. 4, pp. 391-411, 2002.

[15] K. Bulsuk, Artist, Taking the First Step with PDCA. [Art]. https://www.bulsuk.com/, 2008.

[16] M. M. M. J. a. S. N. Teli, "PDCA Cycle As TQM Toolcontinuous improvement of warranty," Int. J. Recent Technol. Mech. Electr. Eng, vol. 2, no. 4, pp. 1-5, 2015.

[17] S. Isniah and F. D. H. H. Purba, "Plan do check action (PDCA) method: literature review," Jurnal Sistem dan Manajemen Industri, vol. 4, no. 1, pp. 72-81, 2020.

[18] I. 9000:2015, "Quality management systems Fundamentals and vocabulary".

[19] K. Manghani, "Quality assurance: Importance of systems and standard operating procedures," Perspect Clin Res, vol. 2, no. 1 , pp. $34-37,2011$. 